\title{
Potential acceptability of microbicides in HIV prevention in stable marital relationships in Malawi
}

\section{Thomas Bisika}

\begin{abstract}
Background The XVII International Conference on AIDS held in Mexico City in August 2008 emphasised the importance of dual prevention using both vaccines and microbicides in the fight against HIV and AIDS. Microbicides are important because they constitute one of the potentially important female-controlled methods of HIV and sexually transmitted infection prevention, especially in Malawi where the use of the female condom has not yet been fully embraced.
\end{abstract}

Methods A qualitative study utilising focus group discussions was used to assess the acceptability of the microbicide nonoxynol-9 (N-9) as part of the ongoing Preparatory AIDS Vaccine Evaluation (PAVE) studies.

Results The study observed that men oppose the use of $\mathrm{N}-9$, and that although women consider themselves at risk for HIV they caution against the unintended consequence of altering the vaginal environment with the use of microbicides, which can interfere with the men's preference for dry sex.

Discussion and conclusions Although N-9 did not produce the desired results, these can inform the development of other promising microbicide candidates. The study concludes that it is important to pay attention to how new microbicides are formulated rather than just concentrating solely on an individual product's effectiveness.

Keywords dry sex, female-controlled methods, HIV, microbicides, nonoxynol-9

J Fam Plann Reprod Health Care 2009; 35(2): 115-117

(Accepted 10 November 2008)

\section{Introduction}

Today more than 33 million people are living with HIV worldwide and 22.5 million of these people are in Africa. In 2007 alone, 2.5 million new infections were recorded. ${ }^{1}$ Malawi is one of the countries worst hit by the HIV/AIDS epidemic, with an infection rate among the childbearing age group of $16.4 \% .^{2}$ Youths aged $15-24$ years claim $46 \%$ of new HIV infections of which $60 \%$ occur among girls. HIV in Malawi is mainly spread through heterosexual sex and so is a reproductive health issue. ${ }^{3}$ However, HIV/AIDS control efforts are hampered by low voluntary counselling and testing uptake, ${ }^{4}$ which indicates that a significant behaviour change has not yet occurred in Malawi. Worse still, the role of condom use in dual protection has not yet been taken advantage of in Malawi. ${ }^{5}$

Malawi's dilemma is that HIV continues to spread despite high awareness levels of the pandemic and ways to prevent its spread. In order to address the HIV/AIDS problem, the Malawi government adopted an approach aimed at reducing the risk of transmission through intensive mass education on modes of HIV transmission and ways to reduce risk, blood screening, widespread and vigorous use of barrier methods, antibody testing, beneficial disclosure or notification of partners, prevention of mother-to-child transmission services, and medical treatment and management of infected individuals including the introduction of anti-retroviral therapy. 6 Special AIDS prevention programmes in Malawi focus on use of condoms, limiting the number of sexual partners and delay of initiation of sexual relationships in young persons

School of Health System and Public Health, University of Pretoria, Pretoria, South Africa

Thomas Bisika, ScD, Programme Specialist, United Nations Population Fund, Southern Africa Regional Office and Senior Lecturer, University of Pretoria, School of Health Systems and Public Health

Correspondence to: Dr Thomas Bisika, Health Policy and Management, School of Health Systems and Public Health, University of Pretoria, Box 667, Pretoria 0001, South Africa. E-mail: thomas.bisika@up.ac.za

\section{Key message points}

- Men oppose the use of microbicides on the premise that they would not know if women engage in extramarital sex.

- Men's preference for dry sex may constrain the use of microbicides if these are formulated in a way that makes the vagina watery. This means that the way microbicides are formulated is as important as their effectiveness.

- Ensuring that microbicides have contraceptive properties may make their use less controversial in stable marital relationships.

although some social cultural factors have also been associated with HIV transmission. ${ }^{7}$ These social cultural factors have been isolated and targeted in the current fight against HIV/AIDS.

The XVII International AIDS Conference held in Mexico City in August 2008 emphasised the importance of dual prevention using both vaccines and microbicides in the fight against HIV and AIDS. ${ }^{8}$ Microbicides are important because they constitute one of the potentially important female-controlled methods of HIV and sexually transmitted infection (STI) prevention, especially in Malawi where the use of the female condom has not yet been fully embraced. ${ }^{9}, 10$ Furthermore, the ongoing product development research is not likely to produce a vaccine in the near future and the acceptability of such a vaccine among the adult population in Malawi has not yet been documented. Against this background, a study on the acceptability of the microbicide nonoxynol-9 (N-9) was conducted as part of the ongoing Preparatory AIDS Vaccine Evaluation (PAVE) studies being conducted by the Johns Hopkins University and the University of Malawi at the Queen Elizabeth Hospital in Malawi, which included a behavioural component. ${ }^{11}$

Elsewhere, a novel vaginal microbicide called BufferGel ${ }^{\circledR}$ was tested for acceptability by users as this is an aspect clinical trials generally overlook. Although some women reported that the product made the vagina wet, the majority reported that they would use the product if it were available and proven efficacious, and if they perceived that 
they were at risk of STIs. ${ }^{12}$ The fact that some microbicides make the vagina wet should not be underrated in a country like Malawi where the use of topical agents to produce tightening of the vagina has been reported although this has already been associated with high HIV-1 transmission. ${ }^{13}$ This suggests a preference for dry sex (i.e. a situation where a tight vagina is preferred during sexual intercourse). Studies have shown that N-9 as a microbicides does not reduce the rate of HIV, gonorrhoea or chlamydia infection. ${ }^{14}$ It is, therefore, less surprising that N-9 has been ruled out as a microbicide. ${ }^{15}$ Although this might be the case, information collected as part of acceptability studies of this product would guide the development of other substances that might be used topically as a protective barrier against HIV and other STIs. ${ }^{16}$

\section{Objective}

The main objective of the study was to assess the willingness of men and women in stable marital relationships to use viricides/microbicides in STI and HIV/AIDS prevention.

\section{Methods}

The study was descriptive in nature and utilised a qualitative research methodology. A qualitative methodology was preferred in order to uncover the unforeseen concerns of the target population, namely men and women in stable marital relationships. The study was conducted in two sites: Queen Elizabeth Central Hospital (QECH) in Blantyre and the Sugar Corporation of Malawi (SUCOMA) sugar estate at Nchalo in Chikwawa in the southern region of Malawi. The sample comprised 32 women at QECH and 55 male estate workers at SUCOMA estate who were in the age range 15-49 and 18-55 years, respectively. In this exercise, focus group interviews were employed to elicit qualitative information. A total of 32 women already enrolled in the PAVE studies at QECH participated in four focus group discussions (FGDs). A minimum of six and a maximum of 10 women were allowed to participate in each FGD. In Nchalo, 55 estate workers participated in five FGDs/interviews. The sample size was decided on the basis of maximum variability sampling. ${ }^{17}$

An FGD guide was used in the interviews. Each focus group interview was of at least 45 minutes' duration. However, interviews in Nchalo could sometimes last for more than an hour. The participants were asked questions about their knowledge, attitudes and behaviour regarding pregnancy, STIs and HIV/AIDS and also their general attitudes towards a microbicide containing N-9. Questions on sexual behaviour were included in the guide to assess the context in which a microbicide will be used.

The FGDs were facilitated by a social scientist while nurses only assisted with the screening and recruitment of participants. Before introducing the topic of N-9 the participants were shown samples of the product (a gel) and an explanation was provided on how it works.

All the FGDs were recorded using a micro recorder. The interviews were later transcribed and analysed using the manual search and code method ${ }^{18}$ with the aid of WordPerfect ${ }^{\circledR}$ and MultiMate Advantage ${ }^{\circledR}$ software.

\section{Ethical considerations}

Participation in the study was on a voluntary basis. Informed consent was obtained after explaining the nature and intention of the study in the vernacular language of the participants. The participants were informed of their right to withdraw from the process at any stage of the project and no inducements of any form were used to coerce potential respondents.
The interviewer made sure that the FGDs were conducted at a location where the participants were neither seen nor heard by others during the interview process in order to guarantee privacy and free participation. The principle of confidentiality was respected in that all information including field notes and transcriptions of recorded interviews were not released to anybody and the identity of the research subjects was protected by not collecting names and specific areas of residence. Finally, the research team ensured that the interviews did not disrupt the delivery of essential services by not disturbing providers and recruiting FGD participants after the regular clinic had been concluded. The ethical approval for this study was included in the overall ethics approval for the PAVE studies.

\section{Results}

Both men and women demonstrated some knowledge about HIV and AIDS including ways to avoid getting infected. The women in particular reported that they were at risk of HIV infection because they did not know what their husbands were doing outside the home. When the women were asked to give reasons for their suspicion they reported that some husbands seek sex outside the home because the wife does not scream when they are having sex. They observed that prostitutes scream when having sex and this makes the man feel good. Conversely, the women commented that if a wife screams during sex then the husband may label her as a prostitute.

In all the FGDs conducted in both Blantyre and Nchalo both men and women were consistent in mentioning HIV/AIDS, syphilis, gonorrhoea and chancroid as the main STIs affecting their communities. All the groups, however, mentioned that HIV/AIDS was the most serious STI because it has no cure and is ultimately fatal. The most common mode of HIV transmission was cited as having unprotected sex with multiple partners. Women suggested that the most effective means of HIV/AIDS prevention is to avoid sex with multiple partners while men mentioned condom use. With respect to behaviour, both men and women reported that they had changed their behaviour in the advent of an HIV epidemic mainly through avoiding sex with multiple partners.

When the men were asked about the potential use of $\mathrm{N}-9$ they reported that they would not accept the use of $\mathrm{N}-9$ because this would prevent them knowing if the wife was engaging in extramarital sex; the only way for them to know this is when the woman contracts an STI or becomes pregnant when the man is away. The women reported that they would accept the use of N-9 as long as it does not cause the vagina to be extremely wet, as most of the men prefer dry sex. They were of the opinion that some men go outside the marital home in search of dry sex. They also raised the issue of difficulties in the actual use of N-9, especially considering that at certain times the women may not have time to apply the microbicide before engaging in sex.

The women, however, suggested that if N-9 is used within the framework of family planning then the man cannot be suspicious as using it for HIV and STI prevention may suggest mistrust, which is something their husbands might not like. In a similar vein they pointed out that if the vaginal environment is altered then the husband might know that the wife is using some agent in the vagina, which may also create an element of mistrust.

\section{Discussion}

N-9 has since proved to be a disappointment as research has shown the active ingredient in N-9 to be less than ideal 
and in some cases women using N-9 gel had a higher rate of HIV infection than those using a placebo. ${ }^{19} \mathrm{~N}-9$ can also cause epithelial damage, especially if used frequently, which increases the risk of HIV acquisition. The findings from the present study can, however, still be applied to assess the acceptability of other microbicides under development such as Acidform ${ }^{\circledR}$ and BufferGel. ${ }^{20}$ What is important is that products under development should incorporate contraceptive properties and should be in formulations that do not make the vagina more watery as women would not use it for fear of driving their husbands away. This indicates that a powder formulation would be more acceptable to women in Malawi. Perhaps what was even more interesting about this study was the finding that women were more concerned about dry sex than men.

It is clear that men do not want a female-controlled method of HIV prevention, fearing that this may encourage women to engage in extramarital sex knowing that they will be protected from STIs and pregnancy. What these men do not realise is that the women are in fact trying to protect themselves from unfaithful husbands. Since in Malawi the family unit is still primarily a childbearing institution, the use of female-controlled methods like microbicides could be an effective strategy for prevention of mother-to-child HIV transmission.

\section{Conclusions}

Although N-9 did not make it to the finish line in this particular microbicide race, the information collected during its acceptability studies can inform the development of other promising microbicide candidates. It is suggested that in order to be more acceptable to users, any future microbicide should have properties that do not alter the vaginal environment significantly and in addition it should also have some contraceptive properties. This study, therefore, highlights the importance of paying attention to how new microbicides are formulated rather than just concentrating solely on an individual product's effectiveness.

\section{Statements on funding and competing interests}

Funding This study was funded under the behavioural component of the ongoing Preparatory AIDS Vaccine Evaluation (PAVE) Trials being conducted by the Johns Hopkins University in Malawi. Competing interests None identified.

\section{References}

1 United Nations Joint Programme on HIV/AIDS (UNAIDS). Report on the Global AIDS Epidemic. 2008. http://www.unaids org/en/KnowledgeCentre/HIVData/GlobalReport/2008/2008 Global_report.asp [Accessed 31 July 2008]

2 United Nations Joint Programme on HIV/AIDS (UNAIDS). Malawi: Epidemiological Fact Sheet on HIVIAIDS and Sexually Transmitted Infections (2004 Update). http://data.unaids.org/ Publications/Fact-Sheets01/malawi_EN.pdf [Accessed 31 July 2008].

3 Barden-Ofallon J, deGraft-Johnson J, Bisika T, Benson A, Tsui
A. Factors associated with HIV/AIDS knowledge and risk perception in rural Malawi. AIDS Behav 2004; 8: 131-140.

4 deGraft-Johnson J, Paz-Soldan V, Kasote A, Tsui A. HIV voluntary counseling and testing service preferences in a rural Malawi population. AIDS Behav 2005; 9: 475-484.

5 Measure Evaluation. Avoiding Unwanted Pregnancy and STIs: A Rural Malawi District Study. 2004. http://www.popline.org/ docs/1520/276412.html [Accessed 31 July 2008].

6 National AIDS Commission. National HIV/AIDS Policy: A Call for Renewed Action. 2003. http://www.sarpn.org.za/ documents/d0000702/index.php [Accessed 31 July 2008]

7 Bisika T. Cultural factors that affect sexual and reproductive health in Malawi. J Fam Plann Reprod Health Care 2008: 34: 79-80.

8 Benkimoun P. La Conference internationale sur le sida insiste sur le role primordial de la prevention. Le Monde, 6 August 2008; 8.

9 Blogg S, Blogg J. Acceptability of the Female Condom (FEMIDOM) Within a Population of Commercial Sex Workers and Couples in Salima and NkhotaKota, Malawi. Blantyre, Malawi: Johns Hopkins University, 1991.

10 Kornfield R, Namate D. Female Condom Acceptability Among Family Planning Clients of Blantyre. Lilongwe, Malawi: JSISTAFH Project, 1997.

11 Johns Hopkins University. 1994. Preparatory AIDS Vaccine Evaluation Trial Research Protocol (unpublished document).

12 Bentley ME, Morrow KM, Fullem A, Chesney MA, Horton SD, Rosenberg Z, et al. Acceptability of a novel vaginal microbicide during a safety trial among low-risk women. Fam Plann Perspect 2000; 32: 184-188.

13 Dallabetta G, Miotti P, Chiphangwi J, Liomba G, Saah A. Vaginal tightening agents as risk factors for acquisition of HIV. International Conference on AIDS, 20-23 June 1990; 6: 268. http://gateway.nlm.nih.gov/MeetingAbstracts/ma?f=102182163 html [Accessed 31 July 2008].

14 Roddy RE, Zekeng L, Ryan KA, Tamoufé U, Weir SS, Wong EL. A controlled trial of nonoxynol 9 film to reduce male-tofemale transmission of sexually transmitted diseases, $N$ Engl J Med 1998; 339: 504-510.

15 World Health Organization (WHO), CONRAD Program. Safety of Nonoxynol-9 When Used for Contraception (Report from WHO/CONRAD Technical Consultation, October 2001). Geneva, Switzerland: WHO and CONRAD, 2002. http://www.who.int/reproductive-health/rtis/nonoxynol9.html [Accessed 31 July 2008].

16 Shears KH. After N-9, what next? Several potential microbicides are poised to be tested for effectiveness in humans. Network 2003; 22(4). http://www.fhi.org/en/rh/pubs/ network/v22 4/nt2245.htm [Accessed 31 July 2008].

17 Hudelson P. Guidelines for Conducting a Rapid Ethnographic Study of Malaria Case Management. Second Fieldtest Version. Geneva, Switzerland: Programme for Research and Training in Tropical Diseases (TDR), 1995

18 Hardon A, Boonmongkon P, Steefland P, Tan ML, Hongvivatana T, van der Geest T, et al. Applied Health Research Manual: Anthropology of Health and Health Care. Amsterdam, The Netherlands: University of Amsterdam, 1995

19 Richardson BA. Nonoxynol-9 as a vaginal microbicide for the prevention of sexually transmitted infections: its time to move on. JAMA 2002; 287: 1171-1172.

20 Cates W, Rosenburg Z. Vaginal microbicides: what does the future hold? Contemporary OB/GYN Supplement, April 2008. http://www.ipm-microbicides.org/pdfs/english/ipm publications/ 2008/Vaginal\%20Microbicides\%20What\%20does\%20the\%20 future $\% 20$ hold $\% 20$ ZRosenberg $\% 20$ and $\% 20$ WCates $\% 20 \mathrm{Apr}$ 2008.pdf [Accessed 31 July 2008].
Menopause for the MRCOG and Beyond (2nd edn). Margaret Rees. London, UK: RCOG Press, 2008. ISBN-13: 978-1-90475244-8. Pages: 100. Price: $£ 28.00$ (paperback)

For those who have heard Margaret Rees lecture, one can imagine being read to from this book with her typical succinct delivery. This is a nononsense brief guide to all you need to know about the menopause. Although a short book, it is well referenced for further information. The frustrations one has with the book are those one has with the topic in general: one can only make evidence-based judgements where there is evidence and for some common questions from patients, particularly regarding 'natural' remedies, one has to acknowledge there simply is no evidence. However, Dr Rees includes useful information about diet and lifestyle that should be used in everyday practice.

Perhaps the most useful part of the book is the guidance on explaining risk to patients. It is instructive to doctors and will help reassure those women for whom hormone replacement therapy is an appropriate treatment for their symptoms Pragmatic and clear advice is provided throughout the book, for example, when not to measure follicle-stimulating hormone levels.
I would recommend this book to all health professionals and trainees. For those taking MRCOG or MFSRH qualifications this is manageable, clear reading that will help with essay writing (adopt this style!) and also with objective structured clinical examinations (OSCEs), where consultation skills are assessed. For those beyond, useful revision and reminders make this book merit its space on your bookshelf.

Reviewed by Clare Lipetz, MRCOG, MFRSH Consultant in Sexual and Reproductive Health, Gwent, UK 